\title{
Neurological Complications of On-Pump versus Off-Pump Coronary Artery Bypass Graft Surgery
}

\author{
Brunilda Zllami ${ }^{1}$, Entela Basha ${ }^{2}$, Stavri Llazo ${ }^{3}$, Arben Kojqiqi ${ }^{4}$, Andi Kaçani ${ }^{5}$, Bledi Çekrezi ${ }^{6}$, \\ Ilir Alimehmeti ${ }^{7}$, Jera Kruja ${ }^{8}$ \\ ${ }^{1}$ Department of Neurology, American Hospital, Tirana, Albania \\ ${ }^{2}$ Stroke Unit, Service of Neurology, University Hospital Center "Mother Theresa", Tirana, Albania \\ ${ }^{3}$ Service of Anesthesiology, University Hospital Center "Mother Theresa" Tirana, Albania \\ ${ }^{4,5}$ Service of Cardiac Surgery, American Hospital, Tirana, Albania \\ ${ }^{6}$ Department of Radiology, American Hospital, Tirana, Albania \\ ${ }^{7}$ Department of Family and Occupational Health, Faculty of Medicine, University of Medicine, Tirana, Albania \\ ${ }^{8}$ Service of Neurology, University Hospital Center "Mother Theresa”, Tirana, Albania \\ Running Title: Neurological Complications of On-Pump versus Off-Pump CABG
}

\begin{abstract}
Background: Neurological complications following cardiac surgery are serious, debilitating and, sometimes, lifethreatening. Objective: Assessment of neurological complications following on and off pump coronary artery bypass graft surgery. Methods: We evaluated 441 consecutive patients undergoing cardiac surgery at the Service of Cardiac Surgery at the American Hospital from January 2012 October 2016. Patients were intervened following two different procedures: on-pump by pass (ONCABG) surgery or off-pump bypass surgery $(\mathrm{OPCABG})$. The recorded and analyzed data were as following: preoperative status, including age, sex and comorbidities; intraoperative factors, including surgery type and time of surgery, duration of cardiopulmonary bypass, duration of aortic cross clamping, hypothermia, need for blood transfusions; and post operatory outcomes, including neurological complications, type and time of neurological complications, period of intensive care unit treatment. Results: Of all 441 patients, 338 underwent OPCABG and 103 underwent $\mathrm{ONCABG}$ surgery. There were no significant differences between the groups in terms of age, gender and stroke risk factors. Nevertheless the patients undergoing ONCABG surgery presents a significantly higher prevalence of arrhythmia and prior stroke history. Moreover, more patients of the ONCABG group were treated in emergency conditions. As a result, the off-pump technique presented better neurological outcomes in terms of less stroke complications $(4.4 \% \mathrm{vs} .14 .6 \%$, p<0.001), less encephalopathic complications $(4.1 \%$ vs. $14.6 \%$, $p<0.001)$, less seizure complications $(2.1 \%$ vs. $7.8 \%$, $p=0.045)$ and lower in-hospital mortality (1.8\% vs. $6.8 \%, p=0.008)$. Conclusion: In our observational study, the off-pump CABG surgery was associated with lower neurological complications compared to the on-pump CABG surgery.
\end{abstract}

Keywords: On-pump coronary bypass grafting (ONCABG); off-pump coronary bypass grafting (OPCABG); stroke; encephalopathy; inhospital mortality.

\section{Introduction}

Coronary artery bypass grafting $(\mathrm{CABG})$ is one of the most common surgeries performed by the cardiac surgeons. Cardiac surgery became more feasible in the late 1930s with the development of the heart-lung machine by Dr. John Gibbon which enabled cardiopulmonary bypass (CPB) (1)

In 1950, at McGill University in Montreal, QC, Canada, Vineburg and Buller were the first to implant the internal mammary artery (IMA) into the myocardium to treat cardiac ischemia and angina (2)

Benetti, Calafiore, and Subramian in 1973 completed anastomoses on a beating heart. (3)

The principle of the CABG is to re-establish perfusion to the myocardium and there are different approaches to accomplish that. The first factor considered is the utilization of cardiopulmonary bypass (CPB) or on pump surgery and the second is without $\mathrm{CPB}$, off pump.
With the development of cardiopulmonary bypass and cardioplegia, most CABG was performed on pump. However, interest in off-pump coronary artery bypass (OPCAB) surgery had resurgence in the 1990s. Benneti et al and Buffallo et al published their results of nearly 2000 OPCAB patients showing operative safety (4) (5)

Standard CABG employs a midline incision through the sternum, placement of the patient on coronary bypass, arrest of the heart with cardioplegia. Off pump CABG is without use of the cardiopulmonary bypass. This procedure is called "beating heart surgery" and take consideration because is meant to avoid morbidity and mortality associated with cardiopulmonary bypass (systemic inflammatory response, cross clamping of the aorta). This technique is chosen for the patients with contraindications for conventional CABG, as those with extensive ascending aortic atheromatosis and aortic calcifications. Comparison between these two revascularization techniques is still hot point of debate for outcomes regarding morbidity, complication, and graft patency. OPCABG is performed at $15-20 \%$ of all CABG in 


\section{International Journal of Science and Research (IJSR) \\ ISSN (Online): 2319-7064}

Index Copernicus Value (2015): 78.96 | Impact Factor (2015): 6.391

the developed world, but in the developing world and Far East is performed over $80 \%$ of cases.

The incidence of postoperative CVA after CABG ranges from $1.4 \%$ to $3.8 \%$ (6), hypo perfusion (7) and female sex (8)

\section{Methods}

This study is a prospective control analytic study that was conducted in order to assess the neurological complications between on and off pump coronary artery bypass grafting (CABG) techniques. The study was conducted at the American Hospital Tirana from January 2012 to October 2016. Patients were intervened following two different procedures: on-pump by pass (ONCABG) surgery or offpump bypass surgery (OPCABG).

All patients included in the study were subjected to full demographical and medical history (age, sex, comorbidities, previous TIA, CVA, previous myocardial infarction or PCI), routine laboratory investigations, imaging study before surgery that includes carotid duplex and arterial duplex on both limbs for arterial graft.

Also are prescribed variable related to the procedure (on or off pump, emergent or elective surgery, time of cross clamping of the aorta, time of cardiopulmonary bypass, circulatory arrest, need for blood transfusions).

Exclusion criteria were cases of mixed surgeries, as for example $\mathrm{CABG}$ and valve surgery or $\mathrm{CABG}$ and carotid endarterectomy.

Surgical technique and procedure:

On pump surgery. All operations were performed through a median sternotomy. Standard techniques of CPB were used. Both anterograde and retrograde blood cardioplegia cannulas were placed. The aorta was cross-clamped; Full heparinization was used. The distal anastomoses were first performed, followed by the proximal anastomoses. Heparin was reversed following weaning from the CPB. The LIMA to LAD graft was used, where possible.

Off pump surgery: All operations were performed through a median sternotomy. The order of grafting was the LIMA to LAD, followed by other vessel conduits. The Octopus tissue stabilizer (Medtronic, Octopus Tissue Stabilizer) was used to stabilize the beating heart to perform distal anastomoses. Coronary shunts were used to maintain target vessel haemostasis.

\section{Anaesthetic procedure: \\ Non-pulsatile CBP at the flow rate $2.0-2.4 \mathrm{~L} / \mathrm{min} / \mathrm{m}^{2}$ was established using a roller pump (Sarns 8000) the mean arterial pressure $65-90 \mathrm{~mm} \mathrm{Hg}$. Preservation of the myocardium is realized with antegrade cardioplegia with cold crystalloids $\left(4^{\circ} \mathrm{C}\right)$. Cardioplegia is repeated every 30 minutes during the cross clamping. After the cardiopulmonary bypass all the blood was gathered and retransfused if is well tolerated by the patient. The procedure}

is realized at mild hypothermia $32-34^{\circ} \mathrm{C}$. Off pump procedure is realized at normotermia.

After a systematic neurological examination, stroke was defined as a motor-sensory deficit localized to a focal region of the brain, with or without a decreased levels of consciousness, and encephalopathy as a decrease or fluctuations in the level of consciousness, with cognitive deterioration, in the absence of focal motor deficits, after recovery from anaesthesia. (These definitions are adaptations of those accepted by the Society of Thoracic Surgeons.) (9).

\section{Neurological complication diagnosis:}

Diagnosis of CVA firstly is made by surgery team then after confirmed by the neurologist based on the clinical evaluating and imaging. Patient with neurological symptoms underwent at the brain imaging.

\section{Brain imaging:}

Non-contrast Cranial CT (Siemens sensation 64 detectors) or MRI ( Siemens Avanto I-st Class). MRI was also performed (using DWI, GRE, T1-weighted, T2-weighted and FLAIR sequences) in the patients in whom CT revealed nothing abnormal. All the neuroimaging studies were analyzed by an expert neuroradiologist. Ischemic lesions were diagnosed considering the mechanism (atherotrombotic, cardioembolic, hypoperfusion/hypoxia) and taking into account the cerebral vascular territory. Seizures are described by typology.

The patients that had previous TIA or CVA are evaluated by the neurologist before the surgery and after the surgery. For patients with postoperative CVA were prescribe time of stroke. For patients with neurological complication are evaluated for the days spend at stupor and coma and was used CGS (Glasgow coma scale). Was prescribed time in the ICU, hospital history, mortality. Death from stroke included those patients where death was determined to be the direct result of the stroke or from stroke-related complications. This included sepsis with subsequent respiratory failure due to aspiration, hemodynamic collapse due to pulmonary embolism, brain death due to cerebral edema or herniation.

\section{Results}

A total of 441 patients were enrolled in our study, of which 338 underwent off-pump CABG surgery and 103 underwent on-pump CABG surgery. Demographics and baseline data, including differences between patients undergoing off-pump or on-pump CABG surgery, are outlined in Table 1. In brief, there was no significant difference between groups in terms of age, gender, body mass index, and prevalence of diabetes, hypertension, dyslipidemia, kidney failure, smoking and drinking, positive history for myocardial infarction or transient ischemic attack. Nevertheless, patients undergoing off-pump procedures had a lower prevalence of arrhythmia $(13,0 \%$ vs. $26.2 \%, p 0.001)$ and lower positive history of prior stroke $(0.9 \%$ vs. $3.9 \%, p 0.033)$. Importantly, the offpump technique was employed less in emergency surgery, with only $15.1 \%$ of the off-pump cases being emergent interventions, while $36.9 \%$ of the on-pump cases were emergent intervention, $p<0.001$. 
International Journal of Science and Research (IJSR)

ISSN (Online): 2319-7064

Index Copernicus Value (2015): 78.96 | Impact Factor (2015): 6.391

Table 1: Baseline Data of the CABG Surgery Patients

\begin{tabular}{|c|c|c|c|}
\hline Variable & \begin{tabular}{|c|} 
Off-Pump \\
$(\mathrm{n}=338)$
\end{tabular} & $\begin{array}{l}\text { On-Pump } \\
(\mathrm{n}=103)\end{array}$ & $p$-value \\
\hline Age (years) & $63.4 \pm 8.9$ & $64.8 \pm 8.6$ & 0.152 \\
\hline Males (\%) & 79.9 & 77.7 & 0.548 \\
\hline BMI $\left(\mathrm{kg} / \mathrm{m}^{2}\right)$ & $26.7 \pm 3.6$ & $26.3 \pm 3.6$ & 0.349 \\
\hline Diabetes (\%) & 45.0 & 45.6 & 0.907 \\
\hline Hypertension (\%) & 76.0 & 74.8 & 0.794 \\
\hline Dyslipidemia (\%) & 74.0 & 74.8 & 0.872 \\
\hline Smoking (\%) & 56.8 & 64.1 & 0.191 \\
\hline Alcohol (\%) & 28.7 & 28.2 & 0.915 \\
\hline Arrhythmia (\%) & 13.0 & 26.2 & 0.001 \\
\hline Kidney Failure $(\%)$ & 5.9 & 9.7 & 0.182 \\
\hline $\begin{array}{l}\text { History for Myocardial } \\
\text { Infarction }(\%)\end{array}$ & 8.0 & 11.7 & 0.253 \\
\hline $\begin{array}{l}\text { History for Transient Ischemic } \\
\text { Attack }(\%)\end{array}$ & 1.5 & 3.9 & 0.131 \\
\hline History for Stroke (\%) & 0.9 & 3.9 & 0.033 \\
\hline Emergency Surgery (\%) & 15.1 & 36.9 & $<0.001$ \\
\hline
\end{tabular}

As shown in Table 2, a total of 29 patients (6.8\%) were complicated by post-surgery stroke, of which 27 cases $(6.1 \%)$ of ischemic stroke and 3 cases $(0.7 \%)$ of hemorrhagic stroke. Of the all documented strokes, 15 cases occurred in the ONCABG group (14.6\%) and 15 cases occurred in the OPCABG group (4.4\%), thus associating the off-pump technique with a 3.3 -fold lower chances of postsurgery stroke, $p<0.001$.

All three cases of hemorrhagic strokes occurred in the ONCABG group, while the OPCABG group presented no hemorrhagic stroke.

Moreover, the OPCABG group presented lower cases of post-surgery encephalopathy with only 14 cases $(4.1 \%)$, while 15 cases $(14.6 \%)$ occurred in the ONCABG, $p<0.001$.

Likewise, seizures occurred significantly less in the OPCABG group, 7 cases $(2.1 \%)$, than in the ONCABG group, 8 cases $(7.8 \%), p=0.045$.

In-hospital mortality was also significantly lower in the OPCABG group, 6 cases $(1.8 \%)$, comparing to the ONCABG group, 7 cases $(6.8 \%), p=0.008$. While no significant difference between groups in terms of mortality during the follow-up period could be observed, (data not shown).

Table 2: Neurological Complications

\begin{tabular}{|l|c|c|c|}
\hline Variable & $\begin{array}{c}\text { Off-Pump } \\
(\mathrm{n}=338)\end{array}$ & $\begin{array}{c}\text { On-Pump } \\
(\mathrm{n}=103)\end{array}$ & $p$-value \\
\hline Stroke & 4.4 & 14.6 & $<0.001$ \\
\hline Hemorrhagic stroke & 0.0 & 2.9 & $\mathrm{NS}$ \\
\hline Encephalopathy & 4.1 & 14.6 & $<0.001$ \\
\hline Seizures & 2.1 & 7.8 & 0.045 \\
\hline In-hospital mortality & 1.8 & 6.8 & 0.008 \\
\hline Follow-up mortality & 1.8 & 2.9 & $\mathrm{NS}$ \\
\hline \multicolumn{4}{|l}{ Values are percentages (\%). NS - not significant. } \\
\hline
\end{tabular}

\section{Volume 6 Issue 7, July 2017 www.ijsr.net}

Licensed Under Creative Commons Attribution CC BY
The incidence of postoperative CVA after CABG ranges from $1.4 \%$ to $3.8 \%$ ( 6 )

Risk factors include age, previous stroke, diabetes mellitus, hypertension (9), hypo perfusion (7) and female sex (8).

Afilalo et al. published a meta-analysis of fifty nine trials including nearly 9000 patients, comparing on-pump CABG and OPCAB. Postoperative CVA was significantly reduced by $30 \%$ in the OPCAB group (risk ratio (RR) $0.70,95 \% \mathrm{CI}$ : 0.49-0.99). (10)

Kuss and colleagues analyzed 38 propensity matched studies of 123,137 patients and reported highly clinically and statistically significant benefits for off pump surgery for mortality [odds ratio (OR) $0.69 ; 95 \% \mathrm{CI}, 0.60-0.75$ ] and stroke (OR 0.42; 95\% CI 0.33-0.54) as well as renal failure, prolonged ventilation $(P<0.01)$, inotropic support $(P=$ $0.02)$, intra-aortic balloon pump support $(P=0.05)$, wound infection $(P<0.001)$, and red blood cell transfusion $(P<$ 0.0001). (11)

Puskas and colleagues analyzed the STS database of 42,471 patients matched for 32 clinical risks and reported that OPCABG resulted in significant reductions in the risk of death, stroke, MI and major adverse cardiovascular events (12).

But other studies showed no significant differences between two teqniques.

The ROOBY results (randomized on/off bypass) trial was published, reporting the outcomes for 2.203 patients (99\% men) at 18 Veterans Affairs Medical Centres. Neuropsychological outcomes were not different between the groups, and graft patency was higher in the on-pump group $(87.8 \%$ versus $82.6 \%$; $\mathrm{P}=0.01)$ at 12 months.

Another randomized trial, The Coronary Trial (the CABG Off or On Pump Revascularization Study) (13) which review 4752 patients and GOPCABE trial (German OffPump CABG Trial in Elderly Patients (14), with 2539 patients, found that there was no significant difference in overall death, MI, stroke, new renal dialysis or repeat revascularization in any of the trials.

Muller and colleagues, in a Cochrane review, have analyzed 86 randomized trials, involving 10,716 patients. OPCABG resulted in an increased all-cause mortality compared to ONCABG $(3.7 \%$ versus $3.1 \% p=0.04)$. Also they found that there was no significant difference in myocardial infarction, stroke, renal insufficiency or coronary reintervention between the two techniques but that OPCABG resulted in fewer distal anastomoses with a mean reduction of 0.28 grafts $(p<0.001)$. (15)

OPCABG will only reach its full potential to reduce the risk of neurological injury if a true no-touch aortic technique is used. While avoidance of cannulation and cross-clamping of the aorta by itself reduces aortic manipulation and the risk of embolic debris the placement of vein grafts to the ascending 


\section{International Journal of Science and Research (IJSR) \\ ISSN (Online): 2319-7064 \\ Index Copernicus Value (2015): 78.96 | Impact Factor (2015): 6.391}

aorta increases the risk. In a meta-analysis of 11,398 patients from eight studies, Misfield and colleagues reported that the relative risk of neurological injury was $0.46 \quad(95 \%$ confidence intervals $0.29-0.72 ; p=0.0008$ ) when there was complete avoidance of any aortic manipulation (16)

Like in several other studies, in our study, off pump CABG, is shown to be safe, effective and with less neurological complications. The reason for that is avoidance of cardiopulmonary bypass, cross clamp of the aorta and use of sequential anastomosis, also the experience of our surgeons on the off pump technique. One other cause is that emergency $\mathrm{CABG}$ are realised with on pump technique, and those patients present with higher risk for complication.

\section{Conclusion}

In our observational study, the off-pump CABG surgery was associated with lower neurological complications compared to the on-pump CABG surgery

\section{References}

[1] D. K. C. Cooper, Open Heart: The Radical Surgeons Who Revolutionized Medicine, Kaplan, New York, NY, USA, 2010

[2] B. Shrager, "The vineberg procedure: the immediate forerunner of coronary artery bypass grafting," Annals of Thoracic Surgery, vol. 57, no. 5, pp. 1354-1364, 1994

[3] Cremer and S. Fraund, Beating Heart Bypass Surgery and Minimally Invasive Conduit Harvesting, Steinkopff, 2004

[4] Benetti et al. F. J. Benetti, G. Naselli, M. Wood, and L. Geffner, "Direct myocardial revascularization without extracorporeal circulation; Experience in 700 patients," Chest, vol. 100, no. 2, pp. 312-316, 19

[5] E. Buffalo, J. C. S. de Andrade, J. N. R. Branco, C. A. Teles, L. F. Aguiar, and W. J. Gomes, "Coronary artery bypass grafting without cardiopulmonary bypass," Annals of Thoracic Surgery, vol. 61, no. 1, pp. 63-66, 1996

[6] M. Selim, "Perioperative stroke," The New England Journal of Medicine, vol. 356, no. 7, pp. 706-713, 200) Risk factors include age, previous stroke, diabetes mellitus, hypertension (G. M. McKhann, M. A. Goldsborough, L. M. Borowicz Jr. et al., "Predictors of stroke risk in coronary artery bypass patients," Annals of Thoracic Surgery, vol. 63, no. 2, pp. 516-521, 1997

[7] R. F. Gottesman, P. M. Sherman, M. A. Grega et al., "Watershed strokes after cardiac surgery: diagnosis, etiology, and outcome," Stroke, vol. 37, no. 9, pp. 2306-2311, 2006

[8] F. Filsoufi, P. B. Rahmanian, J. G. Castillo, D. Bronster, and D. H. Adams, "Incidence, topography, predictors and long-term survival after stroke in patients undergoing coronary artery bypass grafting," Annals of Thoracic Surgery, vol. 85, no. 3, pp. 862-870, 2008

[9] Baker RA, Andrew MJ, Knight JL. Evaluation of neurologic assessment and outcomes in cardiac surgical patients. Sem Thorac Cardiovas Surg. 2001;13:149-57

[10] G. M. McKhann, M. A. Goldsborough, L. M. Borowicz Jr. et al., "Predictors of stroke risk in coronary artery bypass patients," Annals of Thoracic Surgery, vol. 63, no. 2 , pp. $516-521,1997$

[11] Afilalo, M. Rasti, S. M. Ohayon, A. Shimony, and M. J. Eisenberg, "Off-pump versus on-pump coronary artery bypass surgery: an updated meta-analysis and metaregression of randomized trials," European Heart Journal, vol. 33, no. 10, pp. 1257-1267, 2012

[12] Kuss O, von Salviati B, Börgermann J. Off-pump versus on-pump coronary artery bypass grafting: a systematic review and meta-analysis of propensity score analyses. J Thorac Cardiovasc Surg. 2010;140(4):829-83

[13] Puskas JD, Thourani VH, Kilgo P, Cooper W, Vassiliades T, Vega JD, Morris C, Chen E, Schmotzer BJ, Guyton RA, Lattouf OM. Off-pump coronary artery bypass disproportionately benefits high-risk patients. Ann Thorac Surg.2009;88(4):1142-1147

[14] Lamy A, Devereaux PJ, Prabhakaran D, Taggart DP, Hu S, Paolasso E, Straka Z, Piegas LS, Akar AR, Jain AR, Noiseux N, Padmanabhan C, Bahamondes JC, Novick RJ, Vaijyanath P, Reddy SK, Tao L, Olavegogeascoechea PA, Airan B, Sulling TA, Whitlock RP, Ou Y, Pogue J, Chrolavicius S, Yusuf S, CORONARY Investigators Effects of off-pump and onpump coronary-artery bypass grafting at 1 year. $\mathrm{N}$ Engl J Med. 2013;368(13):1179-1188

[15] Diegeler A, Börgermann J, Kappert U, Breuer M, Böning A, Ursulescu A, Rastan A, Holzhey D, Treede H, Rieß FC, Veeckmann P, Asfoor A, Reents W, Zacher M, Hilker M, GOPCABE Study Group Off-pump versus on-pump coronary-artery bypass grafting in elderly patients. N Engl J Med.2013;368(13):11891198

[16] Møller CH, Penninga L, Wetterslev J, Steinbrüchel DA, Gluud C. Off-pump versus on-pump coronary artery bypass grafting for ischaemic heart disease. Cochrane Database Syst Rev. 2012;3:CD007224

[17] Misfeld M, Potger K, Ross DE, McMillan D, Brady PW, Marshman D, Mathur MN. "Anaortic" off-pump coronary artery bypass grafting significantly reduces neurological complications compared to off-pump and conventional on-pump surgery with aortic manipulation. Thorac Cardiovasc 